\title{
A vivência clínica na formação do enfermeiro
}

\author{
La vivencia clínica en la formación del enfermero \\ Clinical experience in the nurse's training
}

\begin{abstract}
Simone Alves Landim', Gilberto Tadeu Reis da Silva', Nildo Alves Batista"
'Faculdade Santa Marcelina. Unidade de Ensino Itaquera. São Paulo-SP, Brasil. " Universidade Federal de São Paulo. Programa de Pós-Graduação em Ensino em Ciências da Saúde. São Paulo-SP, Brasil.
\end{abstract}

Submissão: 18/02/2010

Aprovação: 25/10/2010

\section{RESUMO}

Realizou-se uma análise da literatura no que se refere à vivência clínica na formação do enfermeiro. Procurou-se identificar a produção científica de dissertações e teses que abordem essa vivência, tendo como base de coleta de dados, o Catálogo de Dissertações e Teses do CEPEn, ABEn Nacional, no período de 2001 a 2006. De um total de 132 resumos relacionados a essa temática, 124 (94\%) utilizavam o descritor educação em enfermagem; 05 (4\%), competência clínica e 03 (2\%), residência e internato. Os resultados evidenciam que a produção científica em vivência clínica, elemento essencial à competência clínica, é incipiente, com ligeiro predomínio de dissertações de mestrado as quais, em sua maioria, utilizam métodos qualitativos, sendo sua distribuição distinta no país.

Descritores: Educação; Enfermagem; Competência clínica; Internato e residência.

\section{ABSTRACT}

It was conduct a review of the literature regarding the clinical experience in nursing education. We sought to identify the scientific production of dissertations and theses that address this experience, basing the data collection on the dissertations and theses catalog produced by CEPEn, Brazilian Nursing Association, in the period of 2001 to 2006. Of a total of 132 abstracts related to this issue, $124(94 \%)$ used nursing education as key word; $05(4 \%)$, the key word clinical competence and $03(2 \%)$, internship and residency. The results show that the scientific production in clinical experience, which is essential to clinical competence, is incipient, with a slight predominance of master's thesis which, in most cases, use qualitative methods, and have distinct distribution in the country.

Key words: Education; Nursing; Clinical Competence; Internship and Residency.

\section{RESUMEN}

Fue realizada una revisión de la literatura sobre la experiencia clínica en la educación de enfermería. Identifico-se la producción científica de disertaciones y tesis que abordan esta experiencia, teniendo por base para obtención de datos los resúmenes de disertaciones y tesis publicados en el catálogo CEPEn, de la Asociación Brasileña de Enfermería, en el período de 2001 a 2006. De un total de 132 resúmenes relacionados con este tema, 124 (94\%) utilizaban la educación de enfermería como palabra clave; $05(4 \%)$, la competencia clínica y $03(2 \%)$, internado y residencia. Estos resultados muestran que la producción científica sobre la experiencia clínica, que es esencial para la competencia clínica, es incipiente, con un ligero predominio de disertaciones de maestría que, en la mayoría de los casos, usaran métodos cualitativos, y tienen una distribución diferenciada en el país.

Palabras clave: Educación; Enfermería; Competencia clínica; Internado y residencia. 


\section{INTRODUÇÃO}

Há algum tempo vários estudos têm sido realizados no âmbito da Enfermagem no sentido de identificar ou analisar, sob várias óticas, a produção do conhecimento, desde aspectos mais gerais, pertinentes a essa produção, a temas específi$\cos ^{(1-2-2)}$. Tais estudos têm gerado um corpo de conhecimentos que nos possibilitam a apreensão do que é produzido e divulgado sob distintos referenciais e perspectivas ${ }^{(4)}$.

De um enfoque inicialmente quantitativo, novos textos foram sendo divulgados envolvendo estudos de natureza qualitativa, considerando o avanço que essa modalidade de investigação vem conquistando em áreas que lidam, cotidianamente, com o humano e as singularidades a ele inerentes ${ }^{(4)}$.

De forma particular, a produção do conhecimento gerado a partir de dissertações e teses em nível de Pós-Graduação tem sido objeto de análise. Assim, no contexto temático dessas investigações, é frequente a busca dos autores por identificar, na produção gerada pelos cursos de Pós-Graduação, artigos referentes a investigações que eles próprios realizam, o que Ihes possibilita visualizar a produção já construída bem como possíveis lacunas que sinalizem para a necessidade de incentivar novos estudos sobre um determinado tema.

Nesse sentido, as informações divulgadas pelos Catálogos do Centro de Estudos e Pesquisas em Enfermagem (CEPEn) (5), da Associação Brasileira de Enfermagem (ABEn), têm sido muito utilizadas pelos profissionais de Enfermagem e, de forma particular, pelos pós-graduandos dessa área, para realização de suas teses e dissertações.

Cabe mencionar que a iniciativa do CEPEn no sentido de elaborar esses catálogos iniciou-se em 1979, quando foi publicado seu primeiro volume. Ressalte-se que, nessa época, o CEPEn tinha como Diretora a Prof. Anayde Corrêa de Carvalho ${ }^{(6)}$. A esse volume, muitos outros se seguiram e o Centro consolidou-se como referência para a produção científica dos enfermeiros no que se refere ao conhecimento gerado pelos cursos de Pós-Graduação. Atualmente, o CEPEn possui o maior banco de teses e dissertações na área, com cerca de quatro mil estudos registrados em seu acervo.

Como docentes na área da Saúde, particularmente de Enfermagem, temos dirigido nossa preocupação para a importância da vivência clínica enquanto estratégia pedagógica essencial para capacitar o discente ao exercício profissional. Acreditamos que esse vivenciar durante os estágios curriculares seja relevante para a construção do conhecimento dos educandos. Assim, consideramos pertinente a realização de um estudo que evidenciasse a produção de conhecimento sobre esse tema de forma a subsidiar o desenvolvimento de novas pesquisas sobre a vivência clínica na formação dos enfermeiros, além de identificar possíveis facetas relacionadas ao processo ensino-aprendizagem nessa área.

Ao pensarmos em tal vivência clínica, emerge uma questão importante, se consideramos que o processo de trabalho em enfermagem inclui atividades de natureza propedêutica e terapêutica específicas, durante as quais o enfermeiro, em sua trajetória profissional, é estimulado a exercitar e vivenciar nas situações de estágio, aprimorando seu julgamento clínico e buscando tomar decisões eficientes, eficazes e humanizadas.

Estudos ressaltam a importância dos estágios na formação pessoal e profissional dos enfermeiros com vista ao desenvolvimento de posturas, habilidades, competências, interação com equipes multidisciplinares, familiares e pacientes, voltadas para abertura de possibilidades de analisar, crítica e reflexivamente, as interfaces do conhecimento teórico e prático ${ }^{16}$ 7).

O julgamento clínico consiste em um processo mental, norteado pelos princípios da ciência e determinado pelo conhecimento, experiência, percepção e intuição do enfermeiro que procura fazer julgamentos com base em evidências, os quais o levam ao diagnóstico de enfermagem, aproximando-se do conceito de competência clínica ${ }^{(8)}$.

Competência clínica pode ser entendida como a capacidade de realizar, aceitavelmente, aqueles deveres diretamente relacionados ao cuidado para com o paciente; é a capacidade de agir eficazmente em uma determinada situação, com base em conhecimentos, mas sem a eles se ater, de forma a mobilizar o todo ou parte de seus recursos cognitivos e afetivos para interagir em situações complexas. Nesse sentido, os recursos devem ser mobilizados e aplicados por meio da ação profissional, em circunstâncias reais do mundo do trabalho e durante a atuação profissional(9).

$\mathrm{O}$ ato de cuidar precisa ser aprendido pelo contato direto do enfermeiro com o paciente e sua família; assim, diferentes cenários de aprendizagem possibilitam o exercício do julgamento clínico na sua formação por interligar ensino e serviço, de forma a estabelecer relações nos diversos contextos da prática assistencial ${ }^{(10)}$.

Dos estudos mencionados, percebemos a importância da vivência clínica na formação do enfermeiro, o que justifica uma análise da construção do corpo de conhecimento sobre esse tema e, nesse sentido, julgamos ser pertinente a realização do presente estudo com a proposta de verificar uma parcela desse conhecimento, gerado pela Pós-Graduação, utilizando catálogos do CEPEn.

Assim, objetivou-se, com este estudo, identificar a produção científica gerada a partir de dissertações e teses na área da Enfermagem, abordando a vivência clínica para a formação do enfermeiro nos cenários de cursos de graduação e pósgraduação, modalidade residência, em um período determinado; e caracterizar essa produção quanto aos seus autores, metodologia adotada, ano de publicação, estado e região de sua procedência.

\section{METODOLOGIA}

Trata-se de pesquisa bibliográfica, descritiva e quantitativa, tendo como fonte de dados todos os volumes do Catálogo de Dissertações e Teses do CEPEn, ABEn, produzidos no período de 2001 a 2006.

Para a busca bibliográfica, foram adotados os seguintes descritores: internato ou residência, educação em enfermagem, competência clínica. Os resumos dos estudos publicados nos Catálogos foram lidos e, posteriormente, classificados, agrupados e sistematizados, segundo os aspectos: temática 
abordada, origem da publicação, metodologia adotada, ano, Estado em que houve a defesa dos estudos. Os resultados e sua apresentação são evidenciados em tabelas e figuras e sua análise baseia-se em números percentuais e absolutos.

\section{RESULTADOS E DISCUSSÃO}

A partir da consulta aos Catálogos mencionados, foram encontrados um total de 132 resumos relacionados ao tema vivência clínica. Destes, 124 (94\%) estudos utilizaram o descritor educação em enfermagem; 05 (4\%), competência clínica e $03(2 \%)$, a residência ou internato e sua articulação com o ensino em enfermagem. A Figura 1 retrata essa distribuição, com mínima produção de estudos envolvendo o tema competência clínica e residência.

\section{Internato ou residência \\ Competência clínica}

\section{Educação enfermagem}

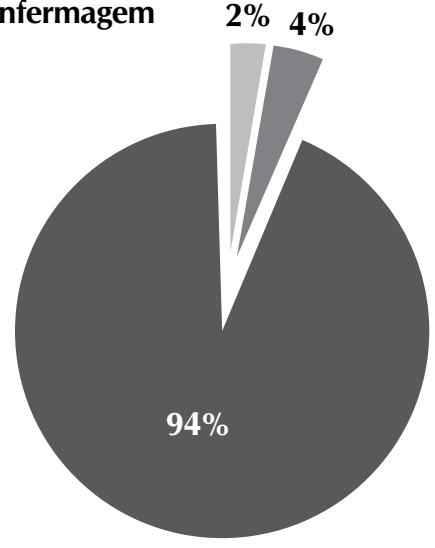

Figura 1- Distribuição de dissertações e teses de PósGraduação em Enfermagem, divulgados pelos Catálogos do CEPEn, de 2001 a 2006, segundo descritores utilizados.

Esses dados expressam o que se pode observar da literatura. O tema educação em enfermagem permite o envolvimento de uma grande amplitude de sub-temas, relacionados às preocupações dos primeiros congressos de enfermagem, enfatizando a necessidade de estudos referentes à educação ou direcionados a diferentes estratégias pedagógicas.

O que se observa, efetivamente, é que a preocupação com a educação vem permeando a produção científica dos enfermeiros desde seus primerios passos em direção aos rumos da investigação. Por outro lado, o conceito de competência clínica é mais recente, carecendo ainda de maior número de estudos um vez que vem se consolidando no cenário de uma enfermagem mais articulada às políticas de saúde, ao contexto de saúde em geral e ao mercado de trabalho. Todos esses fatores requerem que essa tema seja mais contemplado nas investigações.

No que se refere a residência, é uma modalidade que tem crescido face a inúmeras circunstâncias, em virtude da sua recente proposição como modalidade de ensino, interagindo comunidade, pesquisa e ensino. Vem contribuindo para a qualificação dos profissionais do SUS, especialmente em relação à Atenção Primária à Saúde, o que inclui a necessidade do desenvolvimento das competências.

Estudos realizados no ano 2000 já alertavam para um movimento dos órgãos dirigentes da Enfermagem, no Brasil, no sentido de instituir, efetivamente, essa modalidade de pósgraduação $^{(11)}$. Assim, acreditamos que, por estar em processo de expansão nos últimos dois anos, tal modalidade ainda não está sendo suficientemente contemplada pelos enfermerios na realização de suas investigações.

Quanto à origem das produções, houve pequeno predomínio de dissertações de mestrado em Enfermagem (68 - 52\%), comparado a teses de doutorado (64 - 48\%). Esse resultado não pareceu inesperado, considerando que, em geral, os pós-graduandos são estimulados, a partir do mestrado, a prosseguirem seus estudos em direção ao doutorado e, assim, essa similaridade condiz com o que vem ocorrendo. Acresce-se que as universidades públicas passaram a exigir o título de doutor para admissão de docentes. Ainda podemos considerar que o pós-graduando tende a prosseguir investigando, no doutorado, o tema relacionado ao mestrado o que, de certa forma, reafirma a análise quanto à distribuição da produção do conhecimento.

A maior concentração desses estudos ocorreu em três estados brasileiros, a saber: São Paulo (SP), com 76 trabalhos (58\%), Rio de Janeiro (RJ), com 18 (14\%) e Santa Catarina (SC), com 15 (11\%); a esses se seguiram estados com menor evidência em relação à produção sobre o tema, como Minas Gerais (MG), com 05 trabalhos (4\%), Ceará (CE) 04 (3\%), Paraíba (PB) 04 (3\%), Goiás (GO), 03 (2\%). Os estados do Paraná (RN) (1\%), Bahia (BA) $(1 \%)$ e Rio Grande do Norte (RGN) apresentaram 02 (2\%) trabalhos, respectivamente, e o estado do Rio Grande do Sul (RGS), 01 (1\%) trabalho. É possível observar que a grande maioria da produção científica provém da Região Sudeste, sendo a menor produção referente ao Nordeste, com ausência na Região Norte.

Esses dados vão ao encontro dos apresentados pela CAPES e Ministério da Educação, divulgados no $10^{\circ}$ SENADEn (Seminário Nacional de Diretrizes para a Educação em Enfermagem), em 2006. A maior concentração de programas de pós-graduação (mestrado e doutorado) está na Região Sudeste e Sul, principalmente no estado de São Paulo ${ }^{(12)}$. Cabe mencionar que esforços têm sido realizados pelos órgãos federais e estaduais para alterar esse cenário acadêmico. Para tanto, estratégias têm sido criadas por tais órgãos, tais como, a política de Editais, Projetos Temáticos, incentivo ao intercâmbio internacional, de forma a melhor distribuir os recursos de fomento à pesquisa.

Outra variável analisada neste estudo foi o ano de publicação dos trabalhos cujos resultados são apresentados na Tabela 1, evidenciando um crescente avanço nas produções, sendo que a maior frequência ocorreu no ano de 2003. Durante o ano de 2001, houve o menor número de trabalhos, totalizando 15 produções. Vale ressaltar que em 2005 observa-se a ocorrência de 24 produções científicas. A tabela 1 evidencia esses resultados: 
Tabela 1- Distribuição dos resumos publicados nos Catálogos CEPEn, de 2001 a 2006, segundo o ano de defesa e Estado dos Programas de Pós-Graduação.

\begin{tabular}{c|c|c|c|c|c|c|c|c|c|c|c|c}
\hline Ano de defesa & SP & $\mathbf{R ~ J}$ & MG & GO & PR & RS & SC & BA & RN & CE & PB & Total \\
\hline $\mathbf{2 0 0 1}$ & 07 & 01 & 02 & 01 & 00 & 00 & 03 & 00 & 00 & 01 & 00 & 15 \\
\hline $\mathbf{2 0 0 2}$ & 14 & 02 & 00 & 00 & 00 & 00 & 04 & 00 & 00 & 01 & 02 & 23 \\
\hline $\mathbf{2 0 0 3}$ & 17 & 08 & 00 & 00 & 00 & 01 & 01 & 01 & 00 & 01 & 01 & 30 \\
\hline $\mathbf{2 0 0 4}$ & 12 & 04 & 00 & 00 & 01 & 00 & 03 & 00 & 01 & 00 & 00 & 21 \\
\hline $\mathbf{2 0 0 5}$ & 16 & 01 & 02 & 01 & 00 & 00 & 02 & 00 & 01 & 01 & 00 & 24 \\
\hline $\mathbf{2 0 0 6}$ & 11 & 01 & 01 & 01 & 01 & 00 & 02 & 01 & 00 & 00 & 01 & 19 \\
\hline Total & 77 & 17 & 05 & 03 & 02 & 01 & 15 & 02 & 02 & 04 & 04 & 132 \\
\hline
\end{tabular}

Fonte: Catálogos do CEPEn, 2001 a 2006.

No que se refere à abordagem metodológica adotada para realização dos 132 estudos, observa-se que 109, ou seja, (83 $\%$ referem-se a pesquisas realizadas segundo abordagem qualitativa, sendo que apenas 23, ou seja, (17\%) adotaram abordagens quantitativas.

O número de investigações que adotam a modalidade qualitativa vem crescendo desde a década de 1980, quando surgiram pesquisas norteadas por fundamentações teóricas distintas do positivismo e, assim, alguns pesquisadores enfermeiros produziram as primeiras teses de doutorado e dissertações de mestrado adotando outras modalidades de investigação, tais como o materialismo histórico e dialético e a fenomenologia( $^{(4)}$.

As pesquisas qualitativas possibilitaram evidenciar que os campos da saúde e da educação encontram-se, cotidianamente, envolvidos com o humano e, nesse sentido, a perspectiva pela qual concebemos o homem imprime um sentido, uma direção para o nosso pensar e fazer, o que se reflete nas políticas formuladas, nas organizações do trabalho e na construção de relações sociais e interpessoais. Ao se proporem a trabaIhar com o homem em suas relações sociais, esses campos envolvem questões complexas, nem sempre contempladas pela lógica tradicional do pensamento, requerendo o resgate da subjetividade. É desse homem complexo e singular que cuidamos. No campo da saúde, acompanhado o processo saúde-doença como manifestação histórica, construção social e objetiva; no campo da educação, possibilitando novos horizontes em seu vir a ser, contemplando sua inserção no mundo como sujeito crítico, sensível, em permanente construção.

Vale relembrar que a preocupação com a educação em enfermagem no Brasil data desde a criação da ABEn, por meio das discussões realizadas nos congressos, encontros, oficinas, comissões e das publicações de artigos pela Revista Brasileira de Enfermagem. Essa preocupação, associada às transformações no campo ideológico, político e econômico do país, contribuiu para que essa entidade consolidasse esse compromisso com a educação em enfermagem, seja na graduação, pós-graduação e ensino médio ${ }^{(12)}$.

Tal compromisso tornou-se ainda mais expressivo com a concretização do Seminário Nacional de Diretrizes para a Educação em Enfermagem (SENADEn), em 1994, o qual constitui-se no fórum de representação da Enfermagem brasileira para discussões de assuntos direcionados ao ensino, à saúde, à educação e à formação de profissionais de enfermagem. Assim, acreditamos que os dados apresentados na Tabela 1, os quais nos mostram um crescimento na produção científica dos enfermeiros, a partir de 2001, no que se refere à educação em enfermagem e à competência clínica, podem ser atribuídos a essa importante contribuição da ABEn na participação de movimentos que contemplem o currículo e educação em enfermagem ${ }^{(13)}$.

\section{CONSIDERAÇÕES FINAIS}

A vivência clínica é considerada essencial para a formação do enfermeiro, pois possibilita o desenvolvimento da competência /julgamento clínico, com base em princípio ampliado de competência como a capacidade de mobilização dos atributos necessários para atuar em face de uma determinada situação, articulando-se de forma pertinente, eficiente e humanizada. Dessa maneira, competência implica em transcender a simples aplicação de recursos; requer a mobilização de atributos diante de uma determinada concepção filosófica e uma dada situação prática profissional, considerando-se o grau de autonomia e o domínio do estudante no momento de sua formação. Nesse sentido, o estudo alerta para que a postura do professor se revista de importância ímpar, possibilitando que o processo ensino-aprendizagem ocorra de forma adequada, favorecendo a boa interação. Lembramos que vivenciar situações de estágio requer que o professor esteja atento para que tais situações se constituam em fonte primordial de aquisição de conhecimentos, competências e posturas éticas. 
Cabe salientar que a experiência do educando, relacionada aos primeiros contatos com a profissão, imprime valores e atitudes ao ensino prático; nosso século está a exigir que a complexidade do homem seja contemplada, em todas as suas dimensões, havendo, assim, a necessidade de viabilização de recursos para a formação de professores competentes que saibam lidar com os grandes desafios do século XXI. Às escolas formadoras, cabe o compromisso de formar esses profissionais com vistas à capacitação para demandas locais e regionais, compromissadas socialmente.

Dos dados obtidos no presente estudo, observamos uma lacuna na produção científica sobre esta temática, considerando a relação existente entre vivência clínica e a formação do enfermeiro, o que evidencia a necessidade de realização de maior número de estudos abordando essa temática de forma a fortalecer nosso cotidiano enquanto educadores, seja no cenário da graduação e/ou pós-graduação, exercendo, de maneira significativa, o ato de educar.

\section{REFERÊNCIAS}

1. Armaroli MJ. Página do estudante: análise de seu conteúdo em periódico nacional. Rev Paul Enferm. 1984 julho/ set; 4(3):114-20.

2. Rocha SMM, Silva GB. Linhas filosóficas e ideológicas na pesquisa em enfermagem no Brasil. Rev Bras Enferm. 1987; 40(4):214-21

3. Revista da Escola de Enfermagem da Universidade de São Paulo. 2005 dez; 39(esp).

4. Boemer MR, Rocha SMM. A pesquisa em enfermagem: notas de ordem histórica e metodológica. Rev Saúde e Sociedade. 1996; 5(2):77-88.

5. Associação Brasileira de Enfermagem. Centro de estudos e Pesquisas em Enfermagem. Informações sobre pesquisas e pesquisadores em enfermagem. Brasília. [texto na internet]. [Citado 2009 fevereiro 16]. Disponível em: http:// enfermagem.bvs.br/php/level.php?lang = pt\&component $=23 \&$ item $=100$.

6. Bousso RS, Merighi MAB, Riesco MLG, Ângelo M. Estágio curricular em enfermagem: transição de identidades. REEUSP. 2000; 34(2):218-25

7. Ito EE, Takahashi RT. Percepção dos enfermeiros de campo sobre o estágio curricular da graduação de enfermagem realizados em sua unidade de trabalho. (Nota Prévia). REEUSP. 2005; 39(1):109-10.
8. Lima VV. Competência: distintas abordagens e implicações na formação de profissionais de saúde. Interface Comum Saúde Educ. 2005; 9(17):369-79.

9. Nascimento DDG. A Residência Multiprofissional em Saúde da Família como estratégia de formação da força de trabalho para o SUS [dissertação]. São Paulo: Escola de Enfermagem/Universidade de São Paulo; 2008.

10. Silva DM, Silva EMVB. O ensino clínico na formação em enfermagem. [texto na internet]. [Citado 2009 fevereiro 16] Disponível em: http://www.ipv.pt/millenium/Millenium30/8.pdf.

11. Barros ALBL, Michel JLM. Cursos de Especialização em enfermagem - Modalidade Residência: experiência de implementação em um Hospital Escola. Rev Lat-am Enferm. 2000 jan; 8(1).

12. Rodriguez RAP, Erdmann AL. Pós-graduação em enfermagem: conquistas, desafios e perspectivas. Anais do $10^{\circ}$ Seminário Nacional de Diretrizes para a Educação em Enfermagem; Brasília-DF, Brasil; 2006.

13. Mancia JR, Padilha MICS, Reibnitz KS. A contribuição dos SENADEns para a construção das diretrizes curriculares da enfermagem. Anais do $6^{\circ}$ Seminário Nacional de Diretrizes para a Educação em Enfermagem; Teresina-PI-Brasil; 2002. 